\title{
Therapeutic drug monitoring of psychotropic medications
}

\author{
Philip B. Mitchell \\ School of Psychiatry, University of New South Wales, Australia
}

\begin{abstract}
Therapeutic drug monitoring (TDM) of a number of psychotropic medications has proven to be of value, enabling minimization of the limitations of considerable genetic variability in their metabolism and the high rates of poor compliance with many psychiatric disorders. Therapeutic ranges have been established for lithium, some of the tricyclic antidepressants, and clozapine. TDM has also been shown to be useful in avoiding toxicity (as many psychotropics have narrow therapeutic indices), particularly that due to interactions with other compounds.
\end{abstract}

Keywords: TDM, therapeutic drug monitoring, psychotropic, lithium, antidepressants, antipsychotics

\section{Introduction}

While major advances have occurred in the pharmacological management of psychiatric illnesses over recent decades, high rates of poor compliance and considerable genetic variability in the metabolism of psychotropic agents have both meant that the practical application of such treatments has often proven difficult. One means of minimizing such problems has been the use of therapeutic drug monitoring (TDM). At present, TDM of serum concentrations is the only available means of estimating brain levels, but despite the obvious limitations, has proven to be of considerable value. Though nuclear magnetic resonance spectroscopy (NMS) has the ultimate potential to enable measurement of brain drug concentrations, this technique is currently in its infancy.

If the general potential value of TDM for psychotropics is accepted, what are the specific major roles for TDM in psychiatric practice?:

\section{Therapentic ranges}

For some psychotropics, therapeutic ranges have been established. The major relevant classes are the mood stabiliser lithium, some of the tricyclic antidepressants (TCAs), and the 'atypical' antipsychotic clozapine.

\section{Toxicity}

As many of the agents used in psychiatry have narrow therapeutic indices, the capacity to avoid serum ranges

Correspondence: Professor P. B. Mitchell, Mood Disorders Unit, Prince of Wales Hospital, Randwick, NSW 203I, Australia. Tel.: 6I-2-938237II; Fax: 61 2-938237I2; E-mail: phil.mitchell@unsw.edu.au where there is a high likelihood of severe adverse effects or toxicity is important in clinical practice. In addition to the TCAs, lithium and clozapine, serum levels indicative of an increased risk of toxicity have also been documented for those anticonvulsants with mood stabilizing properties (i.e. carbamazepine and sodium valproate).

Avoidance of toxicity with psychotropics is relevant to both mono-and combination therapies, although different issues pertain to each form of prescribing.

\section{Monotherapy and genetic polymorphisms}

There has been an explosion of knowledge within the last decade concerning those enzymes involved in the metabolism of the psychotropic agents, and in understanding the genetic variability in the activity of these enzymes within different populations. The major focus has been on the cytochrome P450 system. CYP2D6 is responsible for the metabolism of many of the psychotropic agents, though some are also metabolized via CYP1A2, CYP3A3/4 or CYP2C19 (see Table 1).

It is now clear that while the majority of the population demonstrates extensive (or normal) metabolism (EM) by these enzymes, a proportion show poor metabolism (PM), which leads to drug accumulation. Poor metabolism is usually due to an autosomal recessive trait caused by mutation or deletion of both alleles. For some enzymes, e.g. CYP2D6, a small proportion of the population also demonstrate ultra-extensive metabolism (UM), which leads to reduced drug concentrations at standard doses.

While genotyping of CYP450 enzymes has been slow to enter the clinical arena (and still has significant limitations in its sensitivity, even for CYP2D6 [1]), in the future the combination of information from both TDM and genotyping (or phenotyping where this is not 
Table 1 Psychotropic medication substrates of cytochrome P450 isoenzymes.

\begin{tabular}{lccc}
\hline CYP1A2 & CYP2C19 & CYP2D6 & CYP3A3/4 \\
\hline Amitriptyline & Amitriptyline & Amitriptyline & Alprazolam \\
Clomipramine & Citalopram & Clozapine & Carbamazepine \\
Clozapine & Clomipramine & Desipramine & Clozapine \\
Haloperidol & Diazepam & Fluoxetine & Midazolam \\
Imipramine & Imipramine & Haloperidol & Nefazodone \\
Tacrine & Moclobemide & Mianserin & Triazolam \\
& & Nortriptyline & Paroxetine \\
& & Risperidone & Sertraline \\
& & Thioridazine & \\
\end{tabular}

feasible or affordable) should greatly facilitate identification and appropriate management of individuals prone to either excessively high or low serum concentrations of psychotropic agents [2].

\section{Interactions and genetic polymorphisms}

Toxicity may also be caused by impaired CYP450 function as a result of inhibition due to concurrent medications, i.e. there may be drug-induced PM phenotypes (phenocopying). This is a complicated area as drugs that inhibit a specific enzyme may or may not be metabolized by that enzyme.

In all cases it is the EMs that are converted to phenotypic PMs. The genotypic PMs lack sufficient enzyme to have its actions reduced further. In contemporary practice, one of the more common nongenetic causes of impaired metabolism of psychotropic agents such as antipsychotics or TCAs is concurrent prescription of SSRI (selective serotonin reuptake inhibitor) antidepressants [3]. Those SSRIs which are most potent in inhibiting CYP2D6 are paroxetine and fluoxetine; with citalopram, fluvoxamine or sertraline having only a minimal effect on this enzyme [4]. CYP1A2 is inhibited potently by fluvoxamine, while CYP2C19 is moderately inhibited by fluoxetine and fluvoxamine (see Table 2). CYP3A3/4 is strongly inhibited by the $5-\mathrm{HT}_{2}$-receptor antagonist nefazodone, and moderately affected by fluoxetine and fluvoxamine.

\section{Subtherapeutic concentrations}

The obverse problem is that of unacceptably low concentrations, which may be a relevant factor in either failure to respond or relapse. Low concentrations may reflect poor compliance, or less commonly, ultra-extensive metabolism (as described above). It has been suggested that low drug concentrations in EM patients could be treated by inhibiting 2D6 with quinidine but this could produce its own complications. TDM should clarify whether the problem is due to subtherapeutic drug concentrations or to inefficacy of the drug in a particular patient.

Compliance rates are frequently poor in psychiatric practice. Factors in common with other medical disorders include intolerance of adverse effects and difficulty in accepting the need for long-term treatment. (The latter issue is of particular relevance to psychiatric disorders as these are commonly chronic or episodic conditions). Issues specific to psychiatric disorders include impaired insight (particularly relevant to the psychoses) and preference for psychological as opposed to pharmacological management (a not uncommon issue, for example, in the treatment of depression).

Numerous studies of psychotropic medications have indicated high noncompliance rates. A recent review [5] found that patients receiving antipsychotics took an average of $58 \%$ of the recommended medications (ranging from 24 to 90\%). Patients receiving antidepressants had similarly low rates, taking on average $65 \%$ of the recommended amount (range 40-90\%). A review of studies of compliance rates for patients with physical disorders demonstrated a mean rate of $76 \%$ (range 60-92\%). While this difference suggested lower compliance rates in those with psychiatric disorders, the means of measuring compliance in the various studies were not fully comparable between those with physical and psychiatric conditions.

\section{Overdose}

The final rationale for TDM is actual or suspected overdose with psychotropic medications [6]. 
Table 2 Effect of the newer antidepressants in inhibiting the activity of various cytochrome P450 enzymes; based on in vivo studies. All values relate to the percentage reduction in CYP enzyme activity at the usual therapeutic dosage (adapted from [3, 4]).

\begin{tabular}{|c|c|c|c|c|c|c|c|c|}
\hline Enzyme & Citalopram & Fluoxetine & Fluvoxamine & Paroxetine & Sertraline & Mirtazapine & Nefazodone & Venlafaxine \\
\hline CYP1A2 & $-1+$ & $-1+$ & +++ & $-1+$ & $-1+$ & - & - & - \\
\hline CYP2C9/10 & $?$ & $?$ & $?$ & $?$ & + & $?$ & - & - \\
\hline CYP2C19 & $-1+$ & ++ & ++ & ? & + & $?$ & - & - \\
\hline CYP2D6 & + & +++ & + & +++ & + & + & - & - \\
\hline CYP3A3/4 & $?$ & ++ & ++ & $-/+$ & $-1+$ & - & +++ & - \\
\hline
\end{tabular}

Symbols: ? = unknown; $-=$ no effect $+=<50 \%$ change $;++=50-150 \%$ change $+++=>150 \%$ change.

\section{Mood stabilisers}

Mood stabilisers are defined as medications which are both prophylactic for bipolar disorder and effective in the acute treatment of mania. The first mood stabiliser to be recognized was lithium [7,8]. Carbamazepine has also been demonstrated to be effective for bipolar disorder, both acutely and prophylactically $[9,10]$. Sodium valproate is clearly antimanic acutely [11] but prophylactic effectiveness has yet to be confirmed in controlled studies. In most countries, lithium is the most commonly prescribed mood stabiliser, though in the U.S. this drug has been recently overtaken by sodium valproate [12].

\section{Lithium}

Lithium is a monovalent cation that shares many of the physico-chemical properties of other alkaline metals such as sodium and potassium. It is mainly used for acute and prophylactic treatment of bipolar disorder, but is also of value in the augmentation of failed antidepressant courses for unipolar depression and (though less commonly used in clinical practice) for the prophylaxis of unipolar depression.

Clinical issues Rates of noncompliance with lithium are high, with the range from various studies being 18-53\% [13]. In a survey of reasons for poor compliance, Jamison et al. [14] identified four major issues as articulated by patients: a dislike of medication controlling mood; a dislike of the idea of having a chronic illness; feeling depressed; and side-effects, particularly lethargy, decreased coordination and 'dulling' of the senses. In the same study, the three most important reasons for noncompliance as identified by clinicians were: when patients felt well they saw no need to continue medication; patients missed the 'highs' of hypomania; and patients were bothered by the idea of having a chronic illness.

It has been recognized [15] that one of the consequences of noncompliance peculiar to lithium is that rapid discontinuation leads to a very high rate of relapse, greater than the patient's 'natural' pattern. Fifty percent of patients experience relapse within 5 months of rapid discontinuation, with most relapsing into mania rather than depression.

Methods of analysis Lithium concentrations are measured by either flame emission photometry or atomic absorption spectrophotometry. It is preferable to use clotted blood, from which serum can be separated, rather than anticoagulated blood to avoid any confusion in cases in which lithium heparin is used as an anticoagulant. As lithium moves rapidly into erythrocytes, serum should be separated quickly, preferably within $1 \mathrm{~h} \mathrm{[16].}$

Sampling times and intervals Lithium is available in both standard and slow release preparations. It is readily absorbed after oral administration. Standard preparations lead to peak levels in about $4-4.5 \mathrm{~h}$ [17]. Lithium is excreted virtually entirely by the kidneys and has a half-life varying from 8 to $55 \mathrm{~h}$, with a right-skewed distribution and an arithmetic mean of 18-24 h [18]. While the use of slow-release (sustained, controlled-release) preparations has been proposed as a means of diminishing postdose variation in serum concentrations and associated adverse effects, this has yet to be established empirically [19].

The need to monitor lithium levels was first advocated by Talbott [20] after his demonstration that lithium-related deaths in cardiac patients (for whom lithium was being used as a salt substitute) were due to extremely high serum levels. The recognition of substantial variations in lithium levels over a $24 \mathrm{~h}$ period, however, awaited the work of Amdisen [18, 21, 22]. Amdisen proposed the use of a standardized $12 \mathrm{~h}$ serum lithium concentration, which subsequently became the universally accepted mode of monitoring lithium levels. The sample is taken $12 \mathrm{~h}$ $( \pm 30 \mathrm{~min})$ after the last dose of lithium in patients who have been taking the drug in two or more divided dosages, and who have taken all their prescribed tablets at the scheduled hours for the previous $48 \mathrm{~h}$.

Because of the relatively long half-life of lithium, steady state levels do not occur for 5-7 days. As the standardized concentration was determined for divided dosages, a $10 \%$ to $26 \%$ increase in levels can be expected if there is a change to once daily (usually nighttime) dosing [23]. 
There have been advocates of the use of a nomogram to predict the appropriate daily dose of lithium on the basis of the serum concentration $24 \mathrm{~h}$ after a single test dose [24]. Most commonly, however, lithium is commenced in divided dose (e.g. 750-1000 mg daily) and the dose titrated to the appropriate concentration.

Serum concentrations necessary for adequate prophylaxis of bipolar disorder are less than those required for the acute treatment of mania. After a first episode of mania, it is a common practice to continue lithium for about six months to prevent early relapse. There are various guidelines for determining the need for long-term treatment, the major recommendations being those of Angst et al. [25] or the National Institute of Mental Health [26]. Once dosage stabilization is achieved and the acute episode has been resolved, the frequency of monitoring depends on the individual's particular clinical situation, but should in general be no less than every 6 months in stable patients [23].

Therapeutic ranges The American Psychiatric Association Practice Guidelines for the treatment of patients with bipolar disorder [23] recommend that levels be titrated to serum concentrations of $0.5-1.2 \mathrm{mmol} \mathrm{l}^{-1}$ for the acute treatment of mania. For prophylaxis the guidelines are less prescriptive, stating that serum concentrations, 'may be, in some cases, as high as those required for treatment of the acute episode.' It is then stated that the range of $0.6-0.8 \mathrm{mmol}^{-1}$ 'is commonly chosen by patients and their psychiatrists', and that 'for many patients increases in maintenance serum levels will result in a trade-off between greater protection from episodes at the cost of increased side-effects.' The doyen of lithium researchers, Mogens Schou [27] recommended that: '... between 0.5 and $0.8 \mathrm{mmol}^{-1}$ is appropriate for most patients, but adjustment to values outside this range is necessary for some.'

Such divergence of views reflects the inadequacy of the research data base. Only six studies have randomly assigned patients to either dosage or serum concentration groups (with earlier studies being reviewed well by Gelenberg et al. [28]). In the one such study in acute mania, Stokes et al. [29] allocated patients to either placebo, high dose $\left(0.72 \mathrm{mEq} \mathrm{kg}{ }^{-1}\right.$ day $\left.^{-1}\right)$, medium dose $\left(0.5 \mathrm{mEq} \mathrm{kg}^{-1}\right.$ day $\left.^{-1}\right)$ or low dose $\left(0.24 \mathrm{mEq} \mathrm{kg}^{-1} \mathrm{day}^{-1}\right)$ lithium with consequent serum levels of $0.62-2.00 \mathrm{mmol} \mathrm{1}^{-1}$, $0.29-1.62 \mathrm{mmol}^{-1}$, and $0.20-1.05 \mathrm{mmol}^{-1}$, respectively. While high and medium doses were more effective than placebo, the low dose was not.

Of the five studies of maintenance lithium treatment, only two have found a significant difference between serum concentrations. Waters et al. [30] reported more relapses at low $\left(0.3-0.8 \mathrm{mmol} \mathrm{l}^{-1}\right)$ than high concentrations $\left(0.8-1.4 \mathrm{mmol} \mathrm{l}^{-1}\right)$. Gelenberg et al. [31] randomly allocated bipolar patients to either 'low' $\left(0.4-0.6 \mathrm{mmol} \mathrm{l}^{-1}\right) \quad$ or 'standard' concentrations $\left(0.8-1.0 \mathrm{mmol} \mathrm{l}^{-1}\right)$. The 'low level' group had less adverse effects, but more episodes than those in the 'standard' level group. Since that publication, further analyses of the original data have been reported, demonstrating more 'subsyndromal' symptoms [32] and poorer psychosocial functioning [33] in the low range group. One criticism of the original study, however, was that some of the patients in the low level group had a rapid reduction in dosage, suggesting the possibility of 'discontinuation' relapse.

In contrast, Jerram \& McDonald [34] found no differences in recurrence rates between the following groups: $\quad\left(0.49 \mathrm{mmol} \mathrm{l}^{-1} ; \quad 0.50-0.69 \mathrm{mmol} \mathrm{l}^{-1} ; \quad\right.$ and (0.70 mmol $1^{-1}$. Similarly, Coppen et al. [35] found no difference in the outcome of bipolar patients randomly allocated to either continue lithium at a level of $0.8-1.2 \mathrm{mmol} \mathrm{l}^{-1}$ or to decrease to $0.45-0.79 \mathrm{mmol} \mathrm{l}^{-1}$. More recently, Vestergaard et al. [36] found no difference in recurrence rates between groups randomly allocated (in an open study) to $0.8-1.0 \mathrm{mmol}^{-1}$ or $0.5-0.8 \mathrm{mmol} \mathrm{l}^{-1}$.

For lithium augmentation of antidepressants, serum lithium concentrations of at least $0.4 \mathrm{mmol}^{-1}$ are required [37].

Brain lithium levels While not available clinically, a small number of NMS studies do give some hint of future possibilities. Kato et al. [38] found that brain lithium concentrations were half those measured in serum, and that brain (but not serum) concentrations increased markedly during mania. A more recent study [39] found a brain to serum lithium concentration ratio of 0.76 . Jensen et al. [40] found no relationship between brain lithium concentrations at $12 \mathrm{~h}$ and the form of lithium dosing schedule.

Toxicity This normally occurs at serum concentrations of greater than $1.5-2.0 \mathrm{mmol}^{-1}$, though it can occasionally present at 'therapeutic levels' (usually in the elderly) [41]. Levels greater than $3.5 \mathrm{mmol}^{-1}$ are potentially lethal and haemodialysis is recommended [42]. Features of lithium toxicity include: impaired consciousness (ranging from drowsiness to coma), apathy, hyper-reflexia, hypertonia, muscle fasciculations, dysarthria, ataxia, coarse tremor, myoclonus, choreoathetoid movements, seizures, spasticity, cardiac dysrhythmias and acute renal failure. Some symptoms (such as impaired consciousness) may persist beyond the duration of elevated serum levels. While there have been no studies of this phenomenon in patients with toxicity, it is apparent from NMS studies that lithium is eliminated more slowly from the brain than peripherally [43]. 
Interpretative problems Lithium concentrations may be increased by a number of medication classes [44]. Thiazide diuretics are thought to lower lithium clearance by increasing proximal tubular reabsorption [45]. ACE inhibitors also increase concentrations of concomitant lithium, but the mechanism is yet to be determined. Nonsteroidal anti-inflammatory drugs (NSAIDs) also reduce lithium clearance. Although the mechanism of the latter effect is not clear, one hypothesis is that NSAIDs inhibit renal production of endogenous prostaglandins, thereby mediating either sodium retention or reduced renal blood flow and consequently reduced glomerular filtration rates.

Other causes of increased serum lithium concentrations include any cause of reduced glomerular filtration and sodium depletion, vomiting and diarrhoea, or fever.

Cost effectiveness/benefit of monitoring Measurement of serum lithium concentrations is cheap and readily available. Although no formal cost-benefit studies have been undertaken, the advantages in terms of reduced likelihood of toxicity or severe adverse effects, in conjunction with reduction of recurrence rates by the establishment of therapeutic levels, are clearly apparent.

\section{Sodium valproate}

As for epilepsy, the relationship between serum valproate concentrations and mood stabilizing effects is poorly defined [46]. The so-called 'therapeutic' range for epilepsy

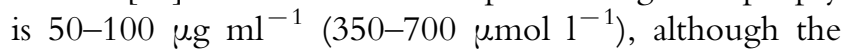
clinical value of this is controversial [47].

The only investigation of the relationship between serum valproate concentration and response in mania has been that of Bowden et al. [48], who undertook a subsiduary analysis of earlier trial data [11]. This study found that, at day 5 , patients with valproate concentrations of at least $45 \mu \mathrm{g} \mathrm{ml}^{-1}\left(315 \mu \mathrm{mol} \mathrm{1}^{-1}\right)$ were 2-7 times as likely as patients with levels less than $45 \mu \mathrm{g} \mathrm{ml} \mathrm{m}^{-1}$ (315 $\mu \mathrm{mol} 1^{-1}$ ) to show at least a $20 \%$ improvement in various mania scales. There was no evidence of any greater benefit from concentrations above $45 \mu \mathrm{g} \mathrm{ml}^{-1}\left(315 \mu \mathrm{mol} \mathrm{l^{-1 }}\right)$, though toxicity was likely at $125 \mu \mathrm{g} \mathrm{ml}^{-1}\left(885 \mu \mathrm{mol} \mathrm{l}^{-1}\right)$ or higher. There have been no studies of randomly allocated doses or concentration ranges of sodium valproate for either the acute treatment of mania or prophylaxis. A theoretical paper on prediction of serum valproate concentrations in psychiatric patients has been published recently [49].

\section{Carbamazepine}

No therapeutic serum concentrations for carbamazepine in bipolar disorder have been established, although in one research setting CSF levels of the -10,11-epoxide metabolite of carbamazepine correlated with the antidepressant efficacy of carbamazepine in a mixed group of patients with unipolar and bipolar disorders [50]. In a randomised controlled trial in recurrent affective disorder, Simhandl et al. [51] found no difference in recurrence rates in bipolar disorder patients between those with low (15-25 $\left.\mu \mathrm{mol} \mathrm{l}^{-1}\right)$ or high $\left(28-40 \mu \mathrm{mol} \mathrm{l}^{-1}\right)$ carbamazepine levels. In practice, as for sodium valproate, therapeutic concentration levels established for epilepsy (6-12 $\mathrm{mg} \mathrm{l}^{-1} ; 20-50 \mathrm{umol} \mathrm{1}^{-1}$ ) are used as a general guideline for patients with bipolar disorder [23].

\section{Antidepressants}

While TDM has been shown to be of clinical utility for a number of tricyclic antidepressants (TCAs) - as will be discussed below - it has not been proven to be of value for the selective serotonin reuptake inhibitor (SSRI) antidepressants. No therapeutic concentration ranges have been demonstrated for any of the SSRIs [52] and toxicity is in general not relevant as thesse drugs have a wide therapeutic index. Among the other antidepressants, only bupropion has been reported by some investigators to have a therapeutic concentration range [53]. No therapeutic ranges have been demonstrated for trazodone, nefazodone, venlafaxine or mirtazapine.

As prescribing of TCAs is becoming less frequent with the growing predominance of the SSRIs and other new antidepressants, TDM for the antidepressants will become less relevant in clinical practice. However, as the TCAs still comprise a significant proportion of antidepressant prescribing, a review of the issues concerning TDM for these medications is still pertinent.

\section{Tricyclic antidepressants (TCAs)}

Clinical issues There are a number of clinical issues which militate against the demonstration of any relationship between TCA concentrations and therapeutic response [54] Depression is considered by many to be a heterogeneous disorder, with some subtypes - such as melancholia - probably responding more predictably to antidepressants. Furthermore, rates of spontaneous remission and placebo response are high in depression, confounding the demonstration of therapeutic concentrations. Despite this, such ranges have been demonstrated for a number of the TCAs. The strongest evidence for therapeutic ranges is for imipramine, desmethylimipramine (desipramine) and nortriptyline.

Methods of analysis While TCAs can be monitored using serum or plasma, serum is preferred as it allows greater ease of extraction and involves no fibrin clots [55]. Serum TCA 
concentration is stable for up to one week at room temperature. A number of different collection techniques have been shown to reduce measured TCA concentrations and should therefore be avoided: heparin-containing tubes; gel separator tubes; and tris-2-butoxyethylphosphate in tube stoppers [55].

The methods available for quantitatively analysing TCAs include immunoassay, h.p.l.c. and gas-liquid chromatography [55-58]. H.p.l.c. with absorbance detection is the most commonly used method. Most reversedphase methods allow simultaneous measurement of both tertiary and secondary amines. Two main immunoassay forms are available: individual methods using the enzymemultiplied immunoassay technique (EMIT); and fluorescence polarization immunoassay (FPIA) technology, which measures total tricyclic levels and is commonly used for urine drug screening rather than blood concentration monitoring.

The EMIT assay involves a solid-phase sample extraction followed by analysis with monoclonal or polyclonal antibodies. While this technique has a dynamic range consistent with therapeutic concentrations of the TCAs, a limitation is the considerable cross-reactivity of tertiary and secondary amine TCAs, as well as with structurally similar drugs such as the antipsychotic chlorpromazine.

Though the FPIA technique was originally developed for urine toxicology screening, its advantage is that no extraction of serum samples is involved. Compared with h.p.l.c., there are considerable negative or positive biases for various TCAs, and there is also considerable crossreactivity with various antidepressants and antipsychotics.

Sampling times and intervals The half-lives of the TCAs are approximately $24 \mathrm{~h}$. The specific half-lives (and days to steady state) of the TCAs for which therapeutic ranges are accepted are: imipramine $6-28 \mathrm{~h}$ ( $2-5$ days), desipramine 12-28 h (3-6 days) and nortriptyline 18-56 h (4-11) days [55]. Because of the long half-lives, most patients take a single evening dose of TCA. Blood samples are taken about $12-14 \mathrm{~h}$ after the last dose for those on once daily treatment, and $4-6 \mathrm{~h}$ after dosing if the patient is on divided dose regimen. Specimens should be taken only once steady state concentrations are likely to have been achieved.

Therapeutic ranges The American Psychiatric Association Task Force on the Use of Laboratory Tests in Psychiatry [59] concluded that there was strong evidence for plasma concentration measurements of imipramine, desmethylimipramine (desipramine) and nortriptyline, but not other TCAs. Subsequent authorities $[54,60]$ have come to similar conclusions.

Studies of both nortriptyline [61, 62] and desipramine [63] have, in general, demonstrated curvilinear con- centration-response relationships, with optimum ranges of $50-150 \mathrm{ng} \mathrm{ml}^{-1}\left(200-600 \mathrm{nmol} \mathrm{l}^{-1}\right)$ and $100-160 \mathrm{ng} \mathrm{ml}^{-1} \quad\left(400-650 \mathrm{nmol} \mathrm{l}^{-1}\right), \quad$ respectively, and response rates of $70 \%$ and $59 \%$, respectively, within these ranges [54]. A recent double-blind 3 year maintenance study [64] of two fixed plasma concentration groups, i.e. $80-120 \mathrm{ng} \mathrm{ml}^{-1}\left(300-450 \mathrm{nmol}^{-1}\right)$ and 40-60 $\mathrm{ng} \mathrm{ml}^{-1}\left(150-230 \mathrm{nmol}^{-1}\right)$, in elderly patients with recurrent depression, found no difference in recurrence rates. The higher level was, however, associated with less residual symptoms, but more constipation.

While imipramine has been found to demonstrate a linear concentration-response relationship, there have been fewer studies of this TCA than with nortriptyline or desipramine. The effective threshold concentration for imipramine is $265 \mathrm{ng} \mathrm{ml}^{-1}\left(1060 \mathrm{nmol} \mathrm{l}^{-1}\right)$, with a remission rate of $42 \%$ at concentrations above this. There is significant risk of first degree atrio-ventricular block above $350 \mathrm{ng} \mathrm{ml}^{-1}\left(1400 \mathrm{nmol}^{-1}\right)$ and delirium above $300 \mathrm{ng} \mathrm{ml}^{-1}\left(1200 \mathrm{nmol}^{-1}\right)$.

Interpretive problems One of the most significant factors underlying the marked interindividual variation in TCA serum concentrations is genetic variation in the activity of CYP450 enzymes, of which CYP2D6, CYP1A2 and CYP3A3/4 are particularly relevant for the TCAs (Table 1) [65, 66]. Furthermore, the activity of CYP1A2 is induced by cigarette smoking [67] which is more common in psychiatric populations.

In the elderly, TCA levels may be increased by reduced hepatic metabolism and blood flow, and changes in the volume of distribution. In children, increased metabolism may necessitate more frequent dosing [68], though TCAs are of limited efficacy and have significant safety concerns in that age group [69].

Hepatic cirrhosis leads to increased TCA concentrations [70]. Renal failure has a minimal effect on the parent TCA compound or demethylated metabolites, but can increase levels of the active hydroxy metabolites which require renal clearance (though these are at low concentrations and are not routinely measured).

Tertiary amine TCAs are mainly demethylated via CYP1A2 and CYP3A3/4, while hydroxylation is via CYP2D6. Hepatic enzyme inducers such as carbamazepine, phenytoin and phenobarbital reduce TCA concentrations, while inhibitors such as SSRI antidepressants [3], antipsychotics or cimetidine increase concentrations, lead to complications such as impaired cardiac conduction or delirium.

Individualization of results Although not commonly used in clinical practice, techniques for prospective pharmacokinetic dosing of nortripytline have been described [71, 
72]. Browne et al. [71] gave patients a 50,75 or $100 \mathrm{mg}$ nighttime dose of nortriptyline. Resulting concentrations were used to determine a maintenance dose to place patients in the 'therapeutic window'.

Cost effectiveness Simmonds et al. [73] found a benefit to cost ratio of 2.5 for the prospective dosing technique of Browne et al. [71], with patients being discharged 6 days earlier and returning to work 55 days earlier than the control group. Preskorn \& Fast [54] calculated that an additional $20 \%$ of patients treated with standard doses of relevant TCAs would respond if TDM were utilized optimally. These authors extrapolated from those figures to estimate savings of US $\$ 45$ per outpatient and US $\$ 455$ per inpatient in terms of improved efficacy. Furthermore, they estimated additional savings in terms of reducing the likelihood of concentration-related adverse effects such as delirium and cardiotoxicity.

\section{Antipsychotics}

In recent years there has been a dramatic shift in the prescribing pattern of antipsychotics, with a rapid increase in usage of the so-called 'atypical' antipsychotics, particularly risperidone and olanzapine. Another 'atypical agent', clozapine, has been demonstrated to be clearly more effective than 'typical' antipsychotics (such as chlorpromazine and haloperidol) in patients with schizophrenia refractory to such agents [74]. As most studies of TDM of antipsychotics have focused on the 'typical' agents, or on clozapine, this section will focus upon these drugs.

Clozapine is $97 \%$ bound to plasma proteins and has a mean half-life of about $12 \mathrm{~h}$ (range 6-33 h). It is metabolized in the liver by CYP1A2 and CYP3A4 to the relatively inactive compounds norclozapine and clozapine-N-oxide. Response to clozapine is therefore not predicted by the CYP2D6 genotype [75].

As would be predicted from a knowledge of the CYP450 metabolizing enzymes, the CYP1A2 inhibitor fluvoxamine increases clozapine concentrations, whereas the CYP3A3/4 inducer carbamazepine decreases levels [76]. Consistent with this, clozapine population pharmacokinetics are distributed similarly to the indices of CYP1A2 activity found in community populations [77]. Despite this, smoking - which induces CYP1A2 activity does not appear to affect clozapine levels [78.]

\section{Methods of analysis}

The most commonly used methods for analysing antipsychotic concentrations are high-performance liquid chromatography (h.p.l.c.) and gas-liquid chromatography (g.c.). H.p.l.c. methods for analysing risperidone [79], olanzapine [80] and clozapine [81] have been reported recently. Radio-immunoassays have been developed for haloperidol and fluphenazine. A biological assay is the radioreceptor assay (RRA) in which a neuroleptic drug and its dopamine blocking metabolites compete with tritiated spiroperidol (or haloperidol) for dopamine $\left(\mathrm{D}_{2}\right)$ binding sites on preparations of membranes from rat striatum [82]. The therapeutic value of RRA has yet to be proven.

\section{Therapeutic ranges}

On the basis of current data, it is reasonable to agree that 'the routine plasma-level monitoring for most of the antipsychotics remains experimental at this point' [83]. There is some evidence of a biphasic or curvi-linear relationship between antipsychotic concentrations and clinical effects [84]. Antipsychotics demonstrating such a response include haloperidol, butaperazine, fluphenazine, perphenazine and thiothixene. The most frequently studied agent has been haloperidol, with some studies indicating a therapeutic window from 5 to $12 \mathrm{ng} \mathrm{ml}^{-1}$

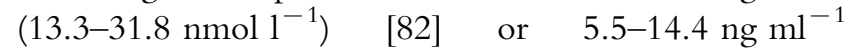
$\left(14.6-38.2 \mathrm{nmol}^{-1}\right)$ [85]. The major uncertainty about such a 'window', however, is whether the upper cut off point represents a true worsening of psychosis or a greater likelihood of adverse effects such as extrapyramidal symptoms or dysphoria (either of which would in turn diminish any subjective therapeutic response).

The one antipsychotic for which data concerning a therapeutic range is sufficiently substantive to justify clinical utilization is the atypical agent clozapine [87]. A number of independent studies have now demonstrated a therapeutic threshold concentration of between 350 and 420 (g/1 (1070-1290 nmol 1-1) [78, 87-90]. Furthermore, in a follow up study of one sample [87], Miller et al. [91] found the concentration-response relationship to be consistent over a 2.5-year period. In addition, five of seven previous nonresponders became responders when plasma clozapine concentrations were increased to above $350 \mu \mathrm{g}$ $1^{-1}\left(1070 \mathrm{nmol} \mathrm{1}^{-1}\right)$.

There is also a relationship between serum clozapine concentrations and CNS adverse effects. For example, Olesen et al. [92] found a significant correlation $(r=0.43)$ between clozapine concentrations and EEG changes. Concentrations above $1000 \mu \mathrm{g} 1^{-1}\left(3060 \mathrm{nmol} \mathrm{l}^{-1}\right)$ significantly increase the risk of confusion, delirium and generalized seizures [86]. There is, however, no evidence to suggest that clozapine-induced agranulocytosis is related to serum concentrations. It should be noted that a recent study has suggested that some patients may be more prone to this complication, with cells from patients with agranulocytosis being less viable than those of patients without agranulocytosis and normal controls after incubation with clozapine and horseradish peroxidase-peroxide [93]. 


\section{Interpretive problems}

Most antipsychotics are metabolized to some extent by CYP2D6. The CYP2D6 genotype has been demonstrated to predict significantly the oral clearance of the 'typical' antipsychotics perphenazine and zuclopenthixol [94]. Conversely, the degree of impairment of CYP2D6 activity has been shown to be related to the severity of extrapyramidal side-effects during neuroleptic treatment [95]. Since these drugs are used long-term there may be a case for phenotyping or genotyping patients at the start of such therapy. This would avoid the interpretive problem that EMs are converted to PMs by phenocopying during long-term therapy.

\section{Conclusions}

In spite of the obvious advantages of TDM in psychiatry, utilization in practice is poor. For example, a recent U.S. survey of Medicaid patients [96] found that 37\% of lithium users, $42 \%$ of valproate users and $42 \%$ of carbamazapine users had not received TDM during the 12 month study period. A similar study in Sweden [97] found use of TDM for antidepressants to be even lower, with only $20 \%$ of psychiatrists (and 2\% of GPs) using TDM for TCAs regularly. Such under-utilization indicates the need for improved education of psychiatrists and clinical pharmacologists on the role of TDM for psychotropic medications.

The author thanks Georgina Barratt-See for typing and preparation. Supported by National Health and Medical Research Council Program Grant 993208 and a New South Wales Health Department Infrastructure Grant Program.

\section{References}

1 Brøsen K, Nielson PN, Brusgaard K, Gram LF, Skjødt K. CYP2D6 genotype determination in the Danish population. Eur J Clin Pharmacol 1994; 47: 221-225.

2 Brøsen K. Drug-metabolizing enzymes and therapeutic drug monitoring in psychiatry. Ther Drug Monit 1996; 18: 393-396.

3 Mitchell PB. Drug interactions of clinical significance with selective serotonin reuptake inhibitors. Drug Safety 1997; 17 (6): 390-406.

4 Greenblatt DJ, von Moltke LL, Harmatz JS, Shader RI. Drug interactions with newer antidepressants: role of human cytochromes P450. J Clin Psychiatry 1998; 59(Suppl 15): 19-27.

5 Cramer JA, Rosenheck R. Compliance with medication regimens for mental and physical disorders. Psychiatric Services 1998; 49: 196-201.

6 Dawson AH, White IM. Overdose and therapeutic drug monitoring. Br J Clin Pharmacol 1999; 48: 278-283.

7 Cade JFJ. Lithium salts in the treatment of psychotic excitement. Med J Aust 1949; 2: 349-352.

8 Baastrup PC, Poulsen JC, Schou M, Thomsen K, Amdisen A. Prophylactic lithium: double-blind discontinuation in manic-depressive and recurrent-depressive disorders. Lancet 1970; 16: 326-330.

9 Okuma $\mathrm{T}$, Inanaga K, Otsuki S, et al. Comparison of the antimanic efficacy of carbamazepine and chlorpromazine: a double-blind controlled study. Psychopharmacology 1979; 66: 211-217.

10 Post RM, Uhde TW, Roy-Byrne P, Joffe RT. Correlates of antimanic response to carbamazepine. Psychiatry Res 1987; 21: 71-83.

11 Bowden C, Brugger AM, Swann AC, et al. Efficacy of divalproex sodium versus lithium in the treatment of mania. JAMA 1994; 271: 918-924.

12 Mitchell PB. The place of anticonvulsants and other putative mood stabilisers in the treatment of bipolar disorder. Aust NZ J Psychiatry, 1999; 33 (Suppl.): S99-S107.

13 Goodwin FK, Jamison KR. Manic-depressive illness. Oxford University Press 1990.

14 Jamison KR, Gerner RH, Goodwin FK. Patient and physician attitudes towards lithium: relationship to compliance. Arch Gen Psychiatry 1979; 36: 866-869.

15 Suppes T, Baldessarini RJ, Faedda GL, Tohen M. Risk of recurrence following discontinuation of lithium treatment in bipolar disorders. Arch Gen Psychiatry 1991; 48: 1082-1088.

16 Aronson JK, Reynolds DJM. Lithium. Br Med J 1992; 305 : 1273-1276.

17 Ward ME, Musa MN, LaGenia B. Clinical pharmacokinetics of lithium. J Clin Pharmacol 1994; 34: 280-285.

18 Amdisen A. Clinical features and management of lithium poisoning. Med Toxicol 1988; 3: 18-32.

19 Kilts CD. The ups and downs of oral lithium dosing. J Clin Psychiatry 1998; 59(Suppl 6): 21-26.

20 Talbott JH. Use of lithium salts as a substitute for sodium chloride. Arch Intern Med 1950; 85: 1-10.

21 Amdisen A. Serum lithium determinations for clinical use. Scand J Clin Lab Invest 1967; 20: 104-108.

22 Amdisen A. Clinical and serum-level monitoring in lithium therapy and lithium intoxication. J Anal Toxicol 1978; 2: 193-202.

23 American Psychiatric Association Practice Guidelines. American Psychiatric Press, Washington DC, 1996.

24 Cooper TB, Berner PE, Simpson GM. The 24-hour serum lithium level as a prognosticator of dosage requirements. $\mathrm{Am}$ J Psychiatry 1973; 130: 601-603.

25 Angst J, Weis $\mathrm{P}$, Grof $\mathrm{P}$, et al. Lithium prophylaxis in recurrent affective disorders. Br J Psychiatry 1970; 116: 604-614.

26 Consensus Development Panel. Mood disorders: Pharmacologic prevention of recurrences. Am J Psychiatry 1985; 142: 469-476.

27 Schou M. Lithium prophylaxis: myths and realities. Am J Psychiatry 1989; 146: 573-576.

28 Gelenberg AJ, Carroll JA, Baudhuin MLS, Jefferson JW, Greist $\mathrm{JH}$. The meaning of serum lithium levels in maintenance therapy of mood disorders: a review of the literature. J Clin Psychiatry 1989; 50:12(Suppl): 17-22, 45-47.

29 Stokes PE, Kocsis JH, Arcuni OJ. Relationship of lithium chloride dose to treatment response in acute mania. Arch Gen Psychiatry 1976; 33: 1080-1084.

30 Waters B, Lapierre YD, Gagnon A, et al. Determination of the optimal concentration of lithium for the prophylaxis of manic depressive disorder. Biol Psychiatry 1982; 17: 1323-1329.

31 Gelenberg AJ, Kane JM, Keller MB, et al. Comparison of 
standard and low serum levels for lithium for maintenance treatment of bipolar disorder. N Engl J Med 1989; 321: 1489-1493.

32 Keller MB, Lavori PW, Kane JM, et al. Subsyndromal symptoms in bipolar disorder. Arch Gen Psychiatry 1992; 49: 371-376.

33 Solomon DA, Ristow WR, Keller MB, et al. Serum lithium levels and psychosocial function in patients with bipolar i disorder. Am J Psychiatry 1996; 153: 1301-1307.

34 Jerram TC, McDonald R. Plasma lithium control with particular reference to minimum effective levels. In Lithium in Medical Practice, eds. Johnson FN, Johnson S, Lancaster, England: MTP Press., pp 407-413., 1978.

35 Coppen A, Abou-Saleh M, Milln P, et al. Decreasing lithium dosage reduces morbidity and side-effects during prophylaxis. J Affective Disorders 1983; 5: 353-362.

36 Vestergaard P, Licht RW, Brodersen A, et al. Outcome of lithium prophylaxis - a prospective follow-up of affective disorder patients assigned to high and low serum lithium levels. Acta Psychiat Scand 1998; 98: 310-315.

37 Stein G, Bernadt M. Lithium augmentation therapy in tricyclic-resistant depression: a controlled trial using lithium in low and normal doses. Br J Psychiatry 1993; 162: 634-640.

38 Kato T, Takahashi S, Inubushi T. Brain lithium concentration by ${ }^{7} \mathrm{Li}$ - and ${ }^{1} \mathrm{H}$-magnetic resonance spectroscopy in bipolar disorder. Psychiatry Res: Neuroimaging 1992; 45: 53-63.

39 Riedl U, Barocka A, Kolem H, et al. Duration of lithium treatment and brain lithium concentrations in patients with uni-polar and schizoaffective disorder - a study with magnetic resonance spectroscopy. Biol Psychiatry 1997; 41: 844-850.

40 Jensen HV, Plenge P, Mellerup ET, et al. Lithium prophylaxis of manic-depressive disorder: daily lithium dosing schedule versus every second day. Acta Psychiatr Scand 1995; 92: 69-74.

41 Speirs J, Hirsch SR. Severe lithium toxicity with 'normal' serum concentrations. Br Med J 1978; 1: 815-816.

42 Gadallah MF, Feinstein EI, Massry SG. Lithium intoxication: clinical course and therapeutic concentrations. Mineral Electrolyte Metab 1988; 14: 146-149.

43 Komoroski PA, Newton JEO, Sprigg JR, et al. In vivo Li nuclear magnetic resonance study of lithium pharmacokinetics and chemical shift imaging in psychiatric patients. Psychiatry Res 1993; 50: 67-76.

44 Finley PR, Warner MD, Peabody CA. Clinical relevance of drug interactions with lithium. Clin Pharmacokin 1995; 29: 172-191.

45 Shirley DG, Walter SJ, Thomsen K. A comparison of micropuncture and lithium clearance methods in the assessment of renal tubular function in rats with diabetes insipidus. Pfiügers Arch 1983; 399: 266-270.

46 Eadie MJ. Therapeutic drug monitoring - antiepileptic drugs. Br J Clin Pharmacol 1998; 46: 183-193.

47 Kilpatrick CJ, Fullinfaw RO, Bury RW, Moulds RFW. Plasma concentrations of unbound valproate and the management of epilepsy. Aust NZ J Med 1987; 17: 574-579.

48 Bowden CL, Janicak PG, Orsulak P, et al. Relation of serum valproate concentration to response in mania. Am J Psychiatry 1996; 153: 765-770.

49 Puentes E, Puzantian T, Lum BL. Prediction of valproate serum concentrations in adult psychiatric patients using bayesian model estimations with NPEM2 population pharmacokinetic parameters. Ther Drug Monit 1999; 21: 351-354.

50 Post RM, Uhde TW, Ballenger JC, Chatterji DC, Greene RF, Bunney WE. Carbamazepine and its -10,11-epoxide metabolite in plasma and csf. Arch Gen Psychiatry 1983; 40: 673-676.

51 Simhandl C, Denk E, Thau K. The comparative efficacy of carbamazepine low and high serum level and lithium carbonate in the prophylaxis of affective disorders. $J$ Affective Disorders 1993; 28: 221-231.

52 Baumann P. Pharmacokinetic-pharmacodynamic relationship of the selective serotonin reuptake inhibitors. Clin Pharmacokin 1996; 31: 444-469.

53 Golden RN, DeVane CL, Laizure SC, Rudorfer MV, Sherer MA, Potter WZ. Bupropion in depression. Arch Gen Psychiatry 1988; 45: 145-149.

54 Preskorn SH, Fast GA. Therapeutic drug monitoring for antidepressants: efficacy, safety and cost effectiveness. J Clin Psychiatry 1991; 52: 6(Suppl): 23-33.

55 Linder MW, Keck PE. Standards of laboratory practice: antidepressant drug monitoring. Clin Chem 1998; 44: 1073-1084.

56 Wong SHY. Methodologies for antidepressant monitoring. Clinics Lab Med 1987; 7: 415-433.

57 Orsulak PJ. Therapeutic monitoring of antidepressant drugs: guidelines updated. Ther Drug Monit 1989; 11: 497-507.

58 Gupta RN. Drug level monitoring. Antidepressants. J Chromatogr 1992; 576: 183-211.

59 American Psychiatric Association Task Force. Tricyclic antidepressants-blood level measurements and clinical outcome. An APA Task Force Report. Am J Psychiatry 1985; 142: 155-162.

60 Perry PJ, Pfohl BM, Holstad SG. The relationship between antidepressant response and tricyclic antidepressant plasma concentrations. Clin Pharmacokin 1987; 13: 381-392.

61 Ziegler VE, Clayton PJ, Taylor JR, Co BT, Biggs JT. Nortriptyline plasma levels and therapeutic response. Clin Pharmacol Ther 1976; 20: 458-463.

62 Vandel S, Vandel B, Sandoz M, Allers G, Bechtel P, Volmat R. Clinical response and plasma concentration of amitriptyline and its metabolite nortriptyline. Eur J Clin Pharmacol 1978; 14: 185-190.

63 Nelson JC, Jatlow P, Quinlan DM, Bowers MB. Desipramine plasma concentration and antidepressant response. Arch Gen Psychiatry 1982; 39: 1419-1422.

64 Reynolds CF, Perel JM, Frank E, et al. Three-year outcomes of maintenance nortriptyline treatment in late-life depression: a study of two fixed plasma levels. Am J Psychiatry 1999; 156: 1177-1181.

65 Linder MW, Prough RA, Valdes R. Pharmacogenetics: a laboratory tool for optimizing therapeutic efficiency. Clin Chem 1997; 43: 254-266.

66 Linder MW, Valdes R. Fundamentals and applications of pharmacogenetics for the clinical laboratory. Ann Clin Lab Sci 1999; 29: 140-149.

67 Madsen H, Kramer Neilsen K, Brøsen K. Imipramine metabolism in relation to the sparteine and mephenytoin oxidation polymorphisms - a population study. $\mathrm{Br} \mathrm{J}$ Clin Pharmacol 1995; 39: 433-439.

68 Geller B, Cooper TB, Schluchter MD, Warham JE, Carr LG. Child and adolescent nortriptyline single dose pharmacokinetic 
parameters: final report. J Clin Psychopharmacol 1987; 7: 321-323.

69 Hazell P, O'Connell D, Heathcote D, Robertson J, Henry D. Efficacy of tricyclic drugs in treating child and adolescent depression: a meta-analysis. Br Med J 1995; 310: 897-901.

70 Preskorn SH, Dorey RC, Jerkovich GS. Therapeutic drug monitoring of tricyclic antidepressants. Clin Chem 1988; 34: 822-828.

71 Browne JL, Perry PJ, Alexander B, et al. Pharmacokinetic protocol for predicting plasma nortriptyline levels. J Clin Psychopharmacol 1983; 3: 351-356.

72 Montgomery SA, McAuley R, Montgomery DB, Braithwaite RA, Dawling S. Dosage adjustment from simple nortriptyline spot level predictor tests in depressed patients. Clin Pharmacokin 1979; 4: 129-136.

73 Simmonds SA, Perry PJ, Rickert ED, Browne JL. Cost-benefit analysis of prospective pharmacokinetic dosing of nortriptyline in depressed inpatients. J Affective Disorders 1985; 8: 47-53.

74 Kane J, Honigfeld G, Singer J, et al. Collaborative study group: clozapine for the treatment-resistant schizophrenic: a double-blind comparison with chlorpromazine. Arch Gen Psychiatry 1988; 45: 789-796.

75 Arranz MJ, Dawson E, Shaikh S, et al. Cytochrome P4502D6 genotype does not determine response to clozapine. Br J Clin Pharmacol 1995; 39: 417-420.

76 Jerling M, Lindström L, Bondesson U, Bertilsson L. Fluvoxamine inhibition and carbamazepine induction of the metabolism of clozapine: evidence from a therapeutic drug monitoring service. Ther Drug Monit 1994; 16: 368-374.

77 Jerling M, Merlé Y, Mentré F, Mallet A. Population pharmacokinetics of clozapine evaluated with the nonparametric maximum likelihood method. $\mathrm{Br} J$ Clin Pharmacol 1997; 44: 447-453.

78 Hasegawa M, Gutierrez-Esteinou R, Way L, Meltzer HY, Breier A, Talbott JA. Relationship between clinical efficacy and clozapine concentrations in plasma in schizophrenia: effect of smoking. J Clin Psychopharmacol 1993; 13: 383-390.

79 Price MC, Hoffman DW. Therapeutic drug monitoring of risperidone and 9-hydroxyrisperidone in serum with solid-phase extraction and high-performance liquid chromatography. Ther Drug Monit 1997; 19: 333-337.

80 Aravagiri M, Ames D, Wirshing WC, Marder SR. Plasma level monitoring of olanzapine in patients with schizophrenia: determination by high-performance liquid chromatography with electrochemical detection. Ther Drug Monit 1997; 19: 307-313.

81 Freeman DJ, Li MC, Oyewumi LK. Solid-phase extraction and high-performance liquid chromatographic analysis of clozapine and norclozapine in human plasma. Ther Drug Monit 1996; 18: 688-692.

82 Van Putten T, Marder SR, Wirshing WC, Aravagiri M, Chabert N. Neuroleptic plasma levels. Schizophrenia Bull 1991; 17: 197-216.
83 Javaid JI. Clinical pharmacokinetics of antipsychotics. J Clin Pharmacol 1994; 34: 286-295.

84 Baldessarini RJ, Cohen BM, Teicher MH. Significance in neuroleptic dose and plasma level in the pharmacological treatment of psychoses. Arch Gen Psychiatry 1988; 45: 79-91.

85 Palao DJ, Arauxo A, Brunet M, et al. Haloperidol: therapeutic window in schizophrenia. J Clin Psychopharmacol 1994; 14: 303-310.

86 Freeman DJ, Oyewumi LK. Will routine therapeutic drug monitoring have a place in clozapine therapy? Clin Pharmacokin 1997; 32: 93-100.

87 Perry PJ, Miller DD, Arndt SV, et al. Clozapine and norclozapine plasma concentrations and clinical response treatment-refractory schizophrenic patients. Am J Psychiatry 1991; 148: 231-235.

88 Potkin SG, Bera R, Gulasekaram B, et al. Plasma clozapine concentrations predict clinical response in treatment-resistant schizophrenia. J Clin Psychiatry 1994; 55 (Suppl B): 133-136.

89 Kronig MH, Munne RA, Szymanski S, et al. Plasma clozapine levels and clinical response for treatment-refractory schizophrenic patients. Am J Psychiatry 1995; 152: 179-182.

90 VanderZwaag C, McGee M, McEvoy JP, Freudenreich O, Wilson WH, Cooper TB. Response of patients with treatment-refractory schizophrenia to clozapine within three serum level ranges. Am J Psychiatry 1996; 153: 1579-1584.

91 Miller DD, Fleming F, Holman TL, Perry PJ. Plasma clozapine concentrations as a predictor of clinical response: a follow-up study. J Clin Psychiatry 1994; 55 (Suppl B): 117-121.

92 Oleson OV, Thomsen K, Jensen PN, et al. Clozapine serum levels and side effects during steady state treatment of schizophrenic patients: a cross-sectional study. Psychopharmacology 1995; 117: 371-378.

93 Tschen AC, Rieder MJ, Oyewumi K, Freeman DJ. The cytotoxicity of clozapine metabolites: implications for predicting clozapine-induced agranulocytosis. Clin Pharmacol Ther 1999; 65: 526-532.

94 Jerling M, Dahl M-L, Åberg-Wistedt A, et al. The CYP2D6 genotype predicts the oral clearance of the neuroleptic agents perphenazine and zuclopenthixol. Clin Pharmacol Ther 1996; 59: 423-428.

95 Arthur H, Dahl M, Siwers B, Sjöqvist F. Polymorphic drug metabolism in schizophrenic patients with tardive dyskinesia. J Clin Pharamacol 1995; 15: 211-216.

96 Marcus SC, Olfson M, Pincus HA, Zarin DA, Kupfer DJ. Therapeutic drug monitoring of mood stabilisers in Medicaid patients with bipolar disorder. Am J Psychiatry 1999; 156: 1014-1018.

97 Isacsson G, Bergman U, Wasserman D, Redfors I, Sjöqvist F. The use of antidepressants and therapeutic drug monitoring by general practitioners and psychiatrists: findings from a questionnaire survey in two Swedish areas. Ann Clin Psychiatry 1996; 8: 153-160. 